\title{
Acute hemorrhagic encephalopathy - diagnostic challenges in a pediatric case
}

\author{
Anca Cristina Drăgănescu*, Monica Luminos ${ }^{1,2}$, Magda Vasile1, Anuța Bilaşco1, Gheorghiță Jugulete ${ }^{1,2}$, \\ Angelica Vişan 1,2, Camelia Kouris ${ }^{1}$, Cristina Negulescu', Cristina Popescu', Mădălina Maria Merişescu, ${ }^{1,2}$ \\ Diana Slavu', Cornelia Dogaru', Sabina Șchiopu', Osman Endis ${ }^{1}$ \\ From The 9th Edition of the Scientific Days of the National Institute for Infectious Diseases Prof Dr Matei Bals \\ Bucharest, Romania. 23-25 October 2013
}

\section{Background}

Acute hemorrhagic encephalomyelitis (AHEM) is considered a rare form of Acute disseminated encephalomyelitis (ADEM), due to acute cerebral vasculitis. The symptomatology consists in similar neurological findings, (meningismus, headache, seizures, multifocal neurologic signs, asymmetrical neurological deficits and coma) with rapid onset of encephalopathy and biphasic evolution. Although previous respiratory disease was registered days before this condition, establishing etiology is quite a challenge, viruses being incriminated.

\section{Case report}

This report shows 10 months-old patient who presented with fever, seizures, multifocal neurological signs, with negative serological findings and initial favorable outcome, who developed severe neurological worsening after 3 weeks of treatment.

First magnetic resonance image (MRI) showed multifocal hyper-intense lesions affecting the CNS white matter. After 3 weeks from the initial symptoms, he had recurrence of his symptoms in association with rapidly progressive refractory status epilepticus and the second MRI showed micro-hemorrhagic lesions.

Aggressive therapeutic management was required in order to avoid the predictable fatal outcome.

\section{Authors' details}

'National Institute for Infectious Diseases "Prof. Dr. Matei Balş", Bucharest, Romania. ${ }^{2}$ Carol Davila University of Medicine and Pharmacy, Bucharest, Romania.

\footnotetext{
* Correspondence: drdraganescu@yahoo.com

'National Institute for Infectious Diseases "Prof. Dr. Matei Balş", Bucharest, Romania
}

Full list of author information is available at the end of the article
Published: 16 December 2013

doi:10.1186/1471-2334-13-S1-P101

Cite this article as: Drăgănescu et al:: Acute hemorrhagic

encephalopathy - diagnostic challenges in a pediatric case. $B M C$

Infectious Diseases 2013 13(Suppl 1):P101.
Submit your next manuscript to BioMed Central and take full advantage of:

- Convenient online submission

- Thorough peer review

- No space constraints or color figure charges

- Immediate publication on acceptance

- Inclusion in PubMed, CAS, Scopus and Google Scholar

- Research which is freely available for redistribution
() Biomed Central
C Biomed Central

(c) 2013 Drăgănescu et al; licensee BioMed Central Ltd. This is an Open Access article distributed under the terms of the Creative Commons Attribution License (http://creativecommons.org/licenses/by/2.0), which permits unrestricted use, distribution, and reproduction in any medium, provided the original work is properly cited. 